\title{
Priming on perceptual implicit memory tests can be achieved through presentation of associates
}

\author{
KATHLEEN B. MCDERMOTT \\ Washington University, St. Louis, Missouri \\ and Washington University School of Medicine, St. Louis, Missouri
}

\begin{abstract}
Roediger and McDermott (1995) presented lists of semantic associates (e.g., door, glass, pane, shade, ledge) to induce false recall of related, nonpresented words (e.g., window). This study procedure was used in an attempt to determine whether associative activation of target words would be sufficient to produce priming on perceptual implicit memory tests. Priming of the nonpresented items occurred on both word stem completion and word fragment completion, but the level of priming was generally lower than for items that had been studied. Priming of the related, nonpresented words occurred on a conceptual implicit test of word association; further, the level of priming was equivalent to that of presented words.
\end{abstract}

Roediger and McDermott (1995) have shown that presenting subjects with associatively related words (e.g., door, glass, pane, shade, ledge) can induce high levels of false recall and false recognition of a related but nonpresented word (e.g., window). This basic observation has since been replicated and extended (e.g., McDermott, 1996; Payne, Elie, Blackwell, \& Neuschatz, 1996; Read, 1996; Robinson \& Roediger, 1997). Most of the related studies have manipulated independent variables and observed the effects on the level of false recall or false recognition. In many ways, the related but not presented words (often called "critical nonpresented words") behave as if they were present in the list: They show testing effects (Roediger \& McDermott, 1995), a greater probability of recall after blocked than random presentation (McDermott, 1996), and diminished false recall under divided attention (Payne, Lampinen, \& Cordero, 1996); finally, metamemory judgments are surprisingly similar for studied and critical nonpresented words (Roediger \& McDermott, 1995; Payne, Elie, et al., 1996), although some differences have been noted (Mather, Henkel, \& Johnson, 1997; Norman \& Schacter, 1997). The goal of the present experiments was to determine whether the related nonpresented words would demonstrate priming on perceptual and conceptual implicit memory tests.

With respect to perceptual implicit memory tests, three predictions are possible. On the basis of the finding that in many ways the critical nonpresented words behave as if they were presented in the list, one might predict that re-

I am grateful to Pat Kyllonen and his colleagues, who are affiliated with the Learning Abilities Measurement Program at Lackland Air Force Base, for providing access to the testing facilities and subjects. I would also like to thank Roddy Roediger for helpful discussion and Bettina Johnson, Kate Pfeifer, and Keith Rozendal for help in coding the data. Correspondence should be addressed to K. B. McDermott, Department of Psychology, Box 1125, Washington University, 1 Brookings Dr., St. Louis, MO 63130-4899 (e-mail: kmcd@npg.wustl.edu). liable priming would occur and that the level of priming would be identical to that for studied words. However, two other, more theoretically driven, predictions are possible. An unresolved question with respect to the critical nonpresented words is whether they are based on unconscious arousal during the study episode (as in Collins \& Loftus's, 1975, spreading activation account) or whether they come consciously to mind during the study phase (as in Underwood's, 1965, notion of implicit associative responses). In the former case, the literature on verbal perceptual implicit memory tests would suggest that no perceptual priming should occur: Activation at the semantic level alone (in the absence of conscious lexical activation) produces no perceptual priming (see, e.g., Weldon, 1991). For example, cross-language priming generally does not occur (Durgunoğlu \& Roediger, 1987), and pictures usually do not prime completion of their visual word forms (McDermott \& Roediger, 1994; Weldon \& Roediger, 1987). However, when a studied word is explicitly thought of (even in the absence of sharing perceptual features with the test word), perceptual priming can occur. For example, generating a word to a conceptual cue (e.g., hot-c___ ) leads to priming (Jacoby, 1983; Masson \& MacLeod, 1992), as does hearing the word (Rajaram \& Roediger, 1993). This abstract priming, which is presumably due to activation of the lexical representation of the word, is typically about half as great as the priming obtained from reading the word.

In summary, one could reasonably make three predictions with respect to the possibility of perceptual priming of the critical nonpresented words. If these words behave as though they were presented, perceptual priming would be equivalent to that of studied words. The implicit memory literature would lead one to predict that if the critical nonpresented word is consciously activated in the study phase, there should be a modest amount of priming of the word. Finally, if there is no conscious activation of the item during study, there should be no perceptual priming. 
Theories of conceptual implicit memory would lead one to make the straightforward prediction that reliable priming of the critical nonpresented word will occur. For example, transfer appropriate processing theory holds that conceptual memory tests (whether explicit or implicit) should behave similarly (Roediger, 1990; Roediger \& Blaxton, 1987); therefore, if false recall is present on free recall, priming of these items should occur on a conceptual implicit memory test. However, Cramer (1965) reported a failed attempt to obtain conceptual priming under conditions similar to those used here, although she did observe both priming of presented items and false recall.

Other empirical results call into question the possibility of obtaining conceptual (and perceptual) priming following presentation of associated words. McDermott and Roediger (1996) failed to find priming on a category association test (as well as a fragment completion test) following presentation of a single associate in the study phase (e.g., study of tusk failed to prime elephant when given the category name animals). In addition, Mandler, Graf, and Kraft (1986) found no stem completion priming (but did find false recognition) following presentation of five words categorically related to their nonpresented targets. Therefore, although theories of conceptual implicit memory would predict priming under the study conditions employed in the present experiments, the existing literature does not demonstrate such effects, albeit with less powerful associative presentations in the study phase.

Four experiments are reported in the present paper. (Actually, Experiments 1-3 were between-subjects conditions of one very large experiment; they are reported separately for ease of exposition.) Experiment 1 demonstrates that under the conditions employed in the present experiments, reliable false recall is obtained. Experiment 2 employs a word association test to demonstrate conceptual priming for the critical items. Experiments 3 and 4 use word stem and word fragment completion tests to show that perceptual priming can be achieved for nonpresented associates of studied items.

A similar logic was used in all experiments. For each associative list presented to subjects, the critical word that links the associates together was sometimes presented in the list and other times not. This manipulation allowed a comparison of performance for presented and nonpresented items across the same sets of items.

\section{EXPERIMENTS 1-3}

The use of implicit memory tests necessitated changes from the standard associative false recall paradigm (Roediger \& McDermott, 1995). Most notably, to disguise the relation between the study and test episodes, the implicit tests occurred after presentation of all the lists (instead of occurring after each individual list). In addition, lists were presented visually (instead of auditorily), and they were shortened (from 15 items to 12). An absence of priming of the critical nonpresented items would be interesting only under conditions in which reliable false recall of these items is observed. Therefore, Experiment 1 used free recall to demonstrate false recall under this set of study conditions. Experiments 2 and 3 used the same study procedure as Experiment 1, but the memory test in Experiment 2 was a conceptual implicit memory test (word association), and in Experiment 3 it was a perceptual implicit memory test (word stem completion).

\section{Method}

Subjects. Subjects were 180 recruits going through basic training at Lackland Air Force Base in San Antonio, Texas. They were tested in groups of 40 or fewer. Sixty subjects participated in each experiment.

Design and Materials. Eighteen 12-item lists were created. These lists were a modified subset of the materials used by Roediger and McDermott (1995, Appendix A). The materials for all experiments in this article can be obtained at the author's website (http://www.artsci.wustl. edu/ ebergman/kath.htm). The lists were truncated and modified so that none of the critical words shared the same ordering of the first three letters with any of the other list words. (This modification was necessary because the test cues in Experiment 3 were three-letter stems, and the stems should correspond to no more than one experimental item.) The lists were divided into three subsets, which were roughly equated on two dimensions: the probability of false recall of the critical nonpresented item and the baseline probability of completing the stem of the critical item with the target word. The latter probabilities were obtained by preexperimentally administering the stem completion task to 151 subjects from the same subject population in an unprimed condition.

An extralist associate was chosen for each list's critical item. These associates were used as cues in the word association test in Experiment 2. The associate was generally only weakly related to the critical item because of this (extralist) restriction; most of the strongest associates occurred in the study list. Extralist associates were thought to be preferable to intralist associates to minimize the chance that subjects would treat the task as an explicit memory test.

Each subject studied two of the three sets of lists. One studied set was assigned to the nonpresented condition, in which the critical item around which the list was constructed was not presented. (Note that the list itself was studied in the nonpresented condition, but the critical linking item [e.g., window] was not present in the studied list.) This condition is the one in which false recall (Experiment 1) and possible priming of nonpresented items (Experiments 2 and 3 ) would be measured. The second set of lists was assigned to the presented condition, in which the critical item appeared in the list; it always replaced the word in the fourth serial position. The third set was not studied and was used to determine baserate responding on the implicit tests. Assignment of list set was completely counterbalanced so that each set served in each condition (presented, nonpresented, nonstudied) an equal number of times across subjects.

Procedure. Subjects in the three test conditions were treated identically in the study phase. They received different treatments beginning at the time of test instruction. Within each experimental session, an approximately equal number of subjects was arbitrarily assigned to each testing condition.

Under intentional learning conditions, subjects were presented with the 12 study lists on a computer screen. They were told that the words they would study would be presented in "small groups" and that they should press the Enter key when prompted, after each group of words. Individual words appeared for $2 \mathrm{sec}$, followed by a $500-\mathrm{msec}$ interstimulus interval.

Following the study procedure, test instructions were administered. Subjects in the free recall condition were given blank sheets of paper and instructed that they should write down as many words as they could recall from the list. Subjects were told that they should be confident that every word they wrote down had been presented in the list (i.e., they were not to guess). The recall period lasted $15 \mathrm{~min}$.

Subjects in the word association condition were given 25 items at test. The test consisted of 18 cues that were associated to the critical items from each of the 18 lists ( 6 items corresponding to each study condition - presented, nonpresented, nonstudied); the test also included 
seven filler items that seemed relatively unassociated with any of the lists Therefore, fewer than half the cues were associated with words that had been studied. Items were ordered randomly on the test. Subjects were told that they were performing a free association task and that there were no right or wrong answers. They were told that they would be given $20 \mathrm{sec}$ in which to write the first six words they generated in response to each cue. After each $20 \mathrm{sec}$, a tone sounded on their computer, signaling them to go to the next cue. As in all of the cued tests in this report, subjects were given cover sheets and asked not to work ahead or go back to any previous items, and the cue always appeared both on the computer screen and the test sheet.

Subjects in the word stem completion condition were given 42 stems to complete with the first word that came to mind. The 42 stems consisted of 18 critical items ( 6 from each of the 3 study conditions), 18 standard items (stems corresponding to list words drawn from positions other than 1,4 , and 12 in the lists - one from each list), and 6 filler items. Therefore, only 18 stems corresponded to words that had been presented during the study phase. Subjects were given $12 \mathrm{sec}$ to complete each stem and were asked to keep pace with the computer.

In summary, all subjects studied 12 lists of words; in half the lists, the critical item was presented, and in the other half it was not. Subjects then took one of three tests: free recall, word association, or word stem completion. Results for each experiment are discussed in turn.

\section{Results and Discussion of Experiment 1: Free Recall}

Shown in Figure 1 are the proportions of items recalled as a function of serial position and study condition. The serial position functions for the two conditions are highly similar, with one exception: recall of the item presented in the fourth serial position. When the critical associate had been presented in the list, it was very well remembered $[.42$, compared with .19 when it had not been presented; $t(59)=6.03$, SEM $=.038]$.

The other points on the serial position curves should look similar because the lists differed only in the particular item that occurred in the fourth serial position. Consistent with past observations, recall of the critical item when it had not been presented in the list occurred with about the same probability (.19) as recall of items from

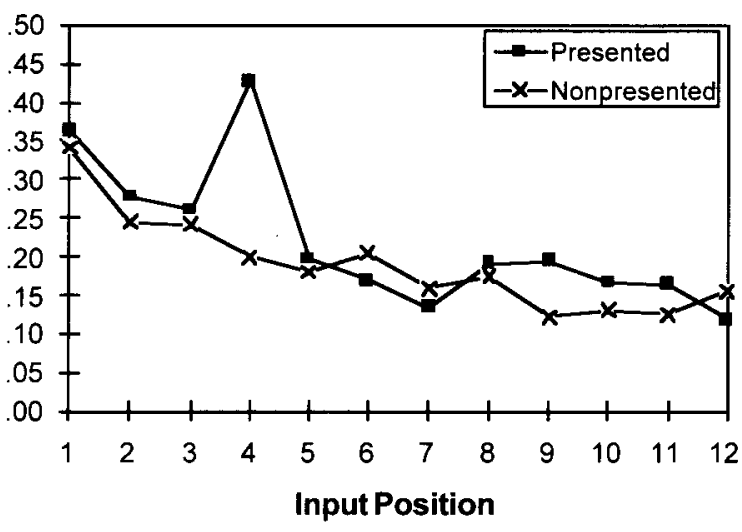

Figure 1. Probability of recall of studied items as a function of study condition and serial position in Experiment 1. Twelve items were studied in both conditions; in the presented condition, the critical linking associate appeared in the list (in the fourth position), but in the nonpresented condition, the linking associate was not presented in the list. (It was, however, erroneously recalled with a probability of .19 .) the flat part of the serial position curve (.16 for items in positions 5-12).

Experiment 1 succeeded in showing that this modified study procedure produced robust false recall. The results also show that the probability of veridical recall of the critical word (when it had been presented in the list) was much greater than the probability of false recall of the same item (when it had been omitted from the list). Therefore, whereas the critical nonpresented associate was recalled with the same probability as other studied items, it was not recalled as if it had been studied in the list.

\section{Results and Discussion of Experiment 2: Word Association}

Results from this experiment were straightforward: Reliable priming of the critical words was observed both when the words had been presented in the list $\left[M_{i}=.08\right.$, $t(59)=3.05, S E M=.026]$ and when they had not been presented $[M=.08, t(59)=2.91, S E M=.027]$. Further, priming of the critical word did not differ as a function of whether or not it had been presented $[t(59)<1]$. Priming occurred above the baserate level of production of 10 for critical words in the nonstudied lists. Unlike in the free recall data, the critical nonpresented items did not differ as a function of the presented/not presented variable; this dissociation between the two conceptual tests suggests that the implicit test probably was not contaminated by intentional recollection. Experiment 3 addressed whether the same pattern of priming would be found on a perceptual implicit memory test.

\section{Results and Discussion of Experiment 3: Word Stem Completion}

Shown in the top three rows of Table 1 are the results for the critical items as a function of whether or not the items had been present (in position 4) in the study list. An inspection of the results suggests that priming existed in both conditions, although to a lesser extent in the nonpresented condition. Statistical analyses indicated that there was reliable priming $(.10)$ of the critical presented items $[t(59)=2.89, S E M=.035]$, but that priming of the critical nonpresented items (.05) was only marginally significant $[t(59)=1.36, S E M=.037, p=.09]$. The difference between the two conditions (presented and nonpresented) was also marginally significant $[t(59)=1.42$, $S E M=.035, p=.08]$.

Although results from this experiment are not definitive, a tentative conclusion is that some intermediate amount of priming did occur for the nonpresented items, but that perhaps the priming produced by presented items was not robust enough to allow for statistical detection of an intermediate value. Because perceptual priming is often obtained in the $20 \%$ range, it is informative to examine the priming scores for the standard list words, or those that were neither critical items nor items sometimes replaced by critical items. Results for these items can be seen in rows 4 and 5 of Table $1 ; .19$ priming occurred for these items. Further, a $t$ test between the prim- 
Table 1

Priming on Perceptual Implicit Memory Tests as a Function of Study Condition

Proportion

Test Type Item Type Study Condition Produced Priming

\begin{tabular}{|c|c|c|c|c|}
\hline \multirow[t]{2}{*}{ Stem completion } & Critical & $\begin{array}{l}\text { Presented } \\
\text { Nonpresented } \\
\text { NS baserate }\end{array}$ & $\begin{array}{l}.48 \\
.43 \\
.38\end{array}$ & $\begin{array}{l}.10 \\
.05\end{array}$ \\
\hline & Standard & $\begin{array}{l}\text { Presented } \\
\text { NS baserate }\end{array}$ & $\begin{array}{l}.37 \\
.18\end{array}$ & .19 \\
\hline \multirow[t]{2}{*}{ Fragment completion } & Critical & $\begin{array}{l}\text { Presented } \\
\text { NS baserate } \\
\text { Nonpresented } \\
\text { NS baserate }\end{array}$ & $\begin{array}{l}.39 \\
.25 \\
.34 \\
.24\end{array}$ & .10 \\
\hline & Standard & $\begin{array}{l}\text { Presented } \\
\text { NS baserate } \\
\text { Nonpresented } \\
\text { NS baserate }\end{array}$ & $\begin{array}{l}.52 \\
.27 \\
.49 \\
.29\end{array}$ & .20 \\
\hline
\end{tabular}

ing levels of critical presented items and standard presented items revealed a significant difference $[t(59)=$ $2.27, S E M=.048]$. Therefore, one reason for the failure to observe reliable differences in priming for the critical items that were or were not presented might be low levels of priming for these items (e.g., they are generally highfrequency words, which tend to produce less priming; see Roediger \& McDermott, 1993, for a review).

\section{EXPERIMENT 4}

Due to the ambiguous nature of the results in the word stem completion experiment, Experiment 4 was performed, with word fragment completion. The goal of the experiment was to use a different perceptual implicit memory test to try to obtain more definitive results with respect to whether perceptual priming occurs for the critical nonpresented items; further, it was hoped that the priming of presented critical items might be more robust than in Experiment 3, thus allowing for a detection of possible differences between the presented and nonpresented conditions.

\section{Method}

Subjects. One hundred recruits from Lackland Air Force Base were tested in groups of 40 or fewer.

Design and Materials. Sixteen critical words were chosen, and the corresponding fragments were normed (on a separate set of 100 subjects) so that the baseline completion rates would approximate .30 . Each subject studied 80 words (sets of 10 words, constructed around 8 critical items); eight lists were not studied so that nonstudied completion rates against which priming was measured could be obtained. The presented/nonpresented variable of the critical items was manipulated between subjects.

The test consisted of 32 fragments, 16 of which corresponded to critical items ( 8 of which corresponded to studied lists, 8 to nonstudied lists), and 16 of which were standard items ( 8 corresponding to studied lists, 8 to nonstudied lists). Fragments were ordered randomly on the test sheet.

Procedure. Subjects were told that they were participating in a study about word comprehension and that they should pay close attention to the words presented because they would later be asked questions about the words. The words were presented in clusters of 10 (grouped accord- ing to list), and subjects were prompted to press the Enter key after each group of 10 words. The words were presented at a 5-sec rate.

At the time of test, subjects were told that they would later receive questions about the presented words, but first they were to complete some word puzzles. They were asked to fill in one letter per blank to form the first English word to come to mind that fit each fragment. They were informed that the task was difficult and that no one was expected to be able to do every puzzle. They were asked to spend $20 \mathrm{sec}$ on each fragment, paced by a tone on the computer. Subjects were instructed to always work on the fragment corresponding to the one on the computer screen and to proceed to the next fragment at the tone.

\section{Results}

Results of this experiment appear in the bottom half of Table 1. Reliable priming of the critical items occurred both when they had been present in the list $[M=.14$, $t(59)=4.23, S E M=.033]$ and when they had not been present $[M=.10, t(59)=3.27, S E M=.031]$. The test of whether priming was greater when the items had been present than when they had not indicated no reliable difference $[t(98)=1.06, S E M=.038, p=.15]$.

Priming of the standard items showed a difference of similar magnitude (.25 priming for the subjects in the presented condition and .20 priming for the subjects in the nonpresented condition). This difference, though, also failed to reach significance $[t(98)=1.02, S E M=$ .049]. Because there is no logical reason the two subject groups should differ in priming of these standard items as a function of whether or not the critical item had appeared in the list, it could simply be that the subjects in the presented condition showed a slightly (but nonsignificantly) higher tendency for priming (both of the standard and critical words).

However, because there are solid theoretical reasons to expect priming of the presented critical items to exceed that of the nonpresented critical items, and because numerical differences in this direction were obtained in both perceptual priming experiments, a reasonable approach is to combine across the two tests (word stem and word fragment completion) in an attempt to resolve the issue of whether priming of the critical item differed as a function of the presented/nonpresented variable. Following Winer $\left(1962\right.$, p. 44), $\chi^{2}$ was calculated on the $t$ values for both experiments. This procedure indicated highly reliable differences between the presented and nonpresented conditions $\left[\chi^{2}(4)=8.85\right]$, as well as highly reliable priming of the critical nonpresented items $\left[\chi^{2}(4)=18.63\right]$. Therefore, the conclusion endorsed here is that priming of the critical nonpresented items was less robust than priming of the same items when they had been presented in the list.

\section{GENERAL DISCUSSION}

The four experiments reported here reveal several new findings. On a final free recall test, when the critical linking items appeared in the study list, these words were recalled at a level far superior to recall of the other studied words. When they did not appear in the list, they were recalled at about the same level as studied items, which replicates past work (e.g., Roediger \& McDermott, 1995). Therefore, although the critical nonpre- 
sented words behaved much like words that had been studied, it is not true that these critical words behaved as though they themselves had been studied. Second, reliable priming of the critical nonpresented item occurred on a conceptual implicit memory test; further, the level of priming was indistinguishable from that of the same items when they had occurred in the study list. Third, perceptual priming occurred for the critical nonpresented items. Whether the magnitude of this priming was equivalent to that of the studied items cannot be conclusively resolved by this data set, but priming for the critical nonpresented words appears to be less than for studied words. Regardless, it is noteworthy that perceptual priming of the critical nonpresented items does occur.

The findings reported here have implications for theories of conceptual priming by adding to the few studies that dissociate conceptual memory tests (Cabeza, 1994; McDermott \& Roediger, 1996). That is, presenting the critical associate doubled the level of free recall of that associate (relative to presenting the relevant list but not the critical linking associate); conversely, these two conditions resulted in identical levels of priming on the conceptual implicit memory test. Therefore, the idea, once endorsed under the transfer appropriate processing framework (see, e.g., Roediger \& Blaxton, 1987), that all conceptual tests should behave in a way similar to free recall is too simplistic.

With respect to theories of false memories, the results are consistent with the interpretation that the critical nonpresented item comes consciously to mind during the study phase in this procedure. Because implicit semantic activation alone generally leads to no perceptual priming, we would expect no perceptual priming if the items did not come to mind consciously. Clearly reliable perceptual priming was obtained for the critical nonpresented items, suggesting conscious activation of the critical nonpresented items at study, at least for some lists. This claim is consistent with the finding of high levels of remember judg. ments for critical nonpresented items (e.g., Roediger \& McDermott, 1995; Payne, Elie, et al., 1996; Schacter, Verfaellie, \& Pradere, 1996) and Mather et al.'s (1997) finding that subjects claim to have rehearsed the items in the study phase.

For both word stem and word fragment completion, more priming occurred for the standard studied items than for the critical studied items. There are two possible explanations for this effect. The first possibility is that some feature of the critical items led to a reduced level of priming for these items. One such feature might be the frequency of critical items, which was substantially higher than that of the standard studied items $(M=74.7$ and 30.7 in Experiment 3 for critical and standard items, respectively, and $M=107.1$ and 26.3 for critical and standard items in Experiment 4; Kučera \& Francis, 1967). A second, more interesting, possibility is that this difference is due to a difference in perceptual processing in the study phase. It could be that the critical items required less perceptual processing for their resolution in the study phase because they were expected in the context of the study list. This hypothesis is supported by the findings that reading an item in context sometimes leads to less perceptual priming than does reading the same item in isolation (see, e.g., Jacoby, 1983). Of course, no definitive statements can be made with respect to this possibility on the basis of the present data, but it does suggest an interesting avenue of investigation for future research.

\section{REFERENCES}

Cabeza, R. (1994). A dissociation between two implicit conceptual tests supports the distinction between types of conceptual process. ing. Psychonomic Bulletin \& Review, 1, 505-508.

Collins, A. M., \& LoFTUS, E. F. (1975). A spreading-activation theory of semantic processing. Psychological Review, 82, 407-428.

Cramer, P. (1965). Recovery of a discrete memory. Journal of Personality \& Social Psychology, 1, 326-332.

DuRgunoĞLU, A. Y., \& RoEDiger, H. L., III (1987). Test differences in accessing bilingual memory. Journal of Memory \& Language, 26, 377-391.

JACOBY, L. L. (1983). Remembering the data: Analyzing interactive processes in reading. Journal of Verbal Learning \& Verbal Behavior, 22, 485-508.
KuČERA, H., \& FRANCIS, W. N. (1967). Computational analysis of presentday American English. Providence, RI: Brown University Press.

Mandler, G., Graf, P., \& KrafT, D. (1986). Activation and elaboration effects in recognition and word priming. Quarterly Journal of Experimental Psychology, 38A, 645-662.

Masson, M. E. J., \& MacLEOD, C. M. (1992). Reenacting the route to interpretation: Enhanced perceptual identification without prior perception. Journal of Experimental Psychology: General, 121, 145-176.

Mather, M., Henkel, L. A., \& Johnson, M. K. (1997). Evaluating characteristics of false memories: Remember/know judgments and memory characteristics questionnaire compared. Memory \& Cognition, 25, 826-837.

MCDERMOTT, K. B. (1996). The persistence of false memories in list recall. Journal of Memory \& Language, 35, 212-230.

MCDeRmott, K. B., \& RoEdiger, H. L., III (1994). Effects of imagery on perceptual implicit memory tests. Journal of Experimental Psychology: Learning, Memory, \& Cognition, 20, 1379-1390.

MCDERmotT, K. B., \& RoEDIGER, H. L., III (1996). Exact and conceptual repetition dissociate conceptual memory tests: Problems for transfer appropriate processing theory. Canadian Journal of Experimental Psychology, 50, 57-71.

Norman, K. A., \& Schacter, D. L. (1997). False recognition in younger and older adults: Exploring the characteristics of illusory memories. Memory \& Cognition, 25, 838-848.

Payne, D. G., Elie, C. J., Blackwell, J. M., \& Neuschatz, J. S. (1996). Memory illusions: Recalling, recognizing, and recollecting events that never occurred. Journal of Memory \& Language, 35, 261-285.

Payne, D. G., Lampinen, J. M., \& Cordero, M. L. (1996, November). Remembrances of things not passed: Further evidence concerning false memories. Paper presented at the annual meeting of the Psychonomic Society, Chicago.

Rajaram, S., \& Roediger, H. L., III (1993). Direct comparison of four implicit memory tests. Journal of Experimental Psychology: Learning, Memory, \& Cognition, 19, 765-776.

READ, J. D. (1996). From a passing thought to a false memory in $2 \mathrm{~min}$ utes: Confusing real and illusory events. Psychonomic Bulletin \& Review', 3, 105-111.

RoBINSON, K. J., \& RoEDIGER, H. L., III (1997). Associative processes in false recall and false recognition. Psychological Science, 8, 231-237.

ROEDIGER, H. L., III (1990). Implicit memory: Retention without remembering. American Psychologist, 45, 1043-1056.

RoEdiger, H. L., III, \& BlaXToN, T. A. (1987). Retrieval modes produce dissociations in memory for surface information. In D. Gorfein \& R. R. Hoffman (Eds.), Memory and cognitive processes: The Ebbinghaus Centennial Conference (pp. 349-379). Hillsdale, NJ: Erlbaum.

RoEdiger, H. L., III, \& MCDERMOTT, K. B. (1993). Implicit memory in normal human subjects. In F. Boller \& J. Grafman (Eds.), Handbook of neuropsychology (Vol. 8, pp. 63-131). Amsterdam: Elsevier.

RoEdiger, H. L., III, \& MCDERMotT, K. B. (1995). Creating false memories: Remembering words not presented in lists. Journal of Experimental Psychology: Learning, Memory, \& Cognition, 21, 803-814.

Schacter, D. L., Verfaellie, M., \& Pradere, D. (1996). The neuropsychology of memory illusions: False recall and recognition in amnesic patients. Journal of Memory \& Language, 35, 319-334.

UNDERWOOD, B. J. (1965). False recognition produced by implicit verbal responses. Journal of Experimental Psychology, 70, 122-129.

WELDON, M. S. (1991). Mechanisms underlying priming on perceptual tests. Journal of Experimental Psychology: Learning, Memory, \& Cognition, 17, 526-541.

WELDON, M. S., \& RoEDIGER, H. L., III (1987). Altering retrieval demands reverses the picture superiority effect. Memory \& Cognition, $17,269-280$.

WINER, B. J. (1962). Statistical principles in experimental design. New York: McGraw-Hill.

(Manuscript received May 9, 1997; revision accepted for publication July 11, 1997.) 